\title{
Author Correction: Meteorin-like facilitates skeletal muscle repair through a Stat3/IGF-1 mechanism
}

Gurpreet S. Baht, Akshay Bareja, David E. Lee, Rajesh R. Rao, Rong Huang @D, Janet L. Huebner, David B. Bartlett, Corey R. Hart, Jason R. Gibson, lan R. Lanza, Virginia B. Kraus, Simon G. Gregory, Bruce M. Spiegelman and James P. White (D)

Correction to: Nature Metabolism https://doi.org/10.1038/s42255-020-0184-y, published online 16 March 2020.

In the version of this article initially published, the name of author Corey R. Hart was incorrectly spelled as Cory R. Hart. The error has been corrected in the HTML and PDF versions of the article.

Published online: 14 July 2020

https://doi.org/10.1038/s42255-020-0257-y

( $)$ The Author(s), under exclusive licence to Springer Nature Limited 2020 